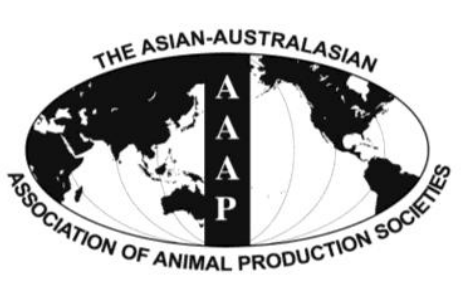

Open Access

Asian Australas. J. Anim. Sci.

Vol. 27, No. 3 : 447-456 March 2014

http://dx.doi.org/10.5713/ajas.2013.13463

www.ajas.info

pISSN 1011-2367 elSSN 1976-5517

\title{
Efficacy of Carcass Electrical Stimulation in Meat Quality Enhancement: A Review
}

\author{
Kazeem Dauda Adeyemi ${ }^{1,3}$ and Awis Qurni Sazili ${ }^{1,2, *}$ \\ ${ }^{1}$ Department of Animal Science, Faculty of Agriculture, Universiti Putra Malaysia, \\ 43400 UPM Serdang, Selangor D.E., Malaysia
}

\begin{abstract}
The use of electrical stimulation (ES) as a management tool to improve meat quality and efficiency of meat processing is reviewed. The basis of the efficacy of ES is its ability to fast track postmortem glycolysis, which in turn stimulates myriad histological, physical, biochemical, biophysical and physiological changes in the postmortem muscle. Electrical stimulation hastens the onset and resolution of rigor mortis thereby reducing processing time and labor and plays a vital role in improving meat tenderness and other meat quality traits. However, ES may have negative impacts on some meat quality traits such as color stability and water holding capacity in some animals. Electrical stimulation is not an end in itself. In order to achieve the desired benefits from its application, the technique must be properly used in conjunction with various intricate antemortem, perimortem and postmortem management practices. Despite extensive research on ES, the fundamental mechanisms and the appropriate commercial applications remained obscured. In addition, muscles differ in their response to ES. Thus, elementary knowledge of the various alterations with respect to muscle type is needed in order to optimize the effectiveness of ES in the improvement of meat quality. (Key Words: Electrical Stimulation, Meat Quality, Tenderness, Postmortem Glycolysis)
\end{abstract}

\section{INTRODUCTION}

Changing trends in the meat industry are crucial factors influencing various interventions to improve or maintain product quality. Recently, the meat industry has transformed from commodity-based to consumer-driven (Troy, 2006). Nowadays, consumers demand convenience, health, safety, taste, uniformity, nutritive value, good appearance and variety of meat and meat products. The need to satisfy consumers' demand necessitates improved research and product development. At postmortem, one of the major interventions adopted in the meat industry for enhancing meat quality traits is carcass electrical stimulation (ES), a

\footnotetext{
* Corresponding Author: Awis Qurni Sazili. Tel: +60-3-89474870, Fax: +60-3-89381024, E-mail: awisqurni@ gmail.com

${ }^{2}$ Halal Products Research Institute, Universiti Putra Malaysia, 43400 UPM Serdang, Selangor D.E., Malaysia.

${ }^{3}$ Department of Animal Production, University of Ilorin, PMB 1515, Ilorin Nigeria.

Submitted Aug. 1, 2013; Accepted Oct. 9, 2013; Revised Nov. 1, 2013
}

practice whereby an electric current is transmitted through the carcass of animals that are freshly slaughtered and eviscerated. In the course of postmortem glycolysis, the muscle undergoes rigor development marked by series of histological, physical and biochemical processes. Therefore, modification of one or more of the processes could eventually alter meat quality traits. The need to curb variability in meat quality traits and to enhance sensory properties of meat necessitate the application of ES. However, it must be realized that the beneficial effects of ES can only be achieved if there is sufficient muscle glycogen before an animal is exsanguinated. This is evident from the study conducted by Dutson et al. (1982) which showed that ES does not affect postmortem $\mathrm{pH}$, color, tenderness and other sensory traits in ante-mortem stressed beef. There are discrepancies among various reports on the influence of ES on meat quality. While some authors reported positive effects (Mckenna et al., 2003; Cetin and Topcu, 2009; Nazli et al., 2010), others reported no effect (Wiklund et al., 2001; Botha et al., 2009; Kim et al., 2013) or in some cases deleterious effects (Hector et al., 1992; den 
Hertog-Meischke et al., 1997; Simmons et al., 2008) of ES on meat quality. These ostensible paradoxes have not been fully resolved in spite of partial insights given by recent reports. Because of this, there is a need to appraise various reports with a view to create a balance in the effective application of ES to optimize meat quality and other merits. Thus, the objective of this review was to assess the roles and applications of ES as a management tool in meat quality enhancement.

\section{Brief history of electrical stimulation}

In 1749, Benjamin Franklin discovered that the flesh of the turkey was tenderized on applying ES shortly postmortem (Lawrie and Ledward, 2006). Some studies had been conducted on ES in the United States during the 1940s. However, such studies failed to yield significant success (Mota-Rojas et al., 2012). Significant application of ES for meat processing took place in the 1950s (Sams, 1999). Thereafter, Harsham and Deatherage filed a patent in 1951 for meat tenderization using ES (Troy, 2006). Harsham and Deatherage (1951) reported that the main effect of ES is to hasten postmortem glycolysis and the basic goal is to swiftly reduce postmortem $\mathrm{pH}$. ES was commercially used in early 1970 s to preclude cold shortening and thus enhance meat tenderness (Juarez et al., 2012). The procedure has been commercially used in various livestock to improve tenderness and other meat quality traits. Electrical stimulation regarded as a step in modifying meat quality traits, has been reported to improve meat sensory properties such as color (Taylor and Martoccia, 1995; Mckenna et al., 2003; Cetin and Topcu, 2009; Nazli et al., 2010), tenderness, flavor and odor (Soria and Corva, 2004; Castaneda et al., 2005; Mota-Rojas et al., 2012).

\section{Types of electrical stimulation}

Presently, there are three major types of ES. These are the extra low-voltage electrical stimulation (ELVES), lowvoltage electrical stimulation (LVES) and high-voltage electrical stimulation (HVES). The ELVES is carried out at voltage of $<100 \mathrm{~V}$ while HVES is carried out at $>110 \mathrm{~V}$. Low voltage electrical stimulation is carried out between $100-110 \mathrm{~V}$ and is often regarded as medium-voltage electrical stimulation (MVES). For the purpose of simplicity, two major types of ES (low and high) are often used in most literature with clear definition of the voltage applied. Except the voltage which is somewhat fixed for the major types of ES, high variability exists in the amperage, impulse frequency, duration of application, type and position of electrode, pathways (through direct or nerve) and delay time between slaughtering and stimulation. The variability in the aforementioned factors accounts for discrepancies in reports regarding the efficacy of ES. In addition, variation in reports could be due to differences in animal age, species, breed, management and handling. Both ES methods yield effective stimulation and have merits and demerits. The ideal method depends on the cost, type of animal, existing slaughter floor restraints and throughput.

Low voltage electrical stimulation is mostly used when there is short delay time (10 to $20 \mathrm{~min}$ ) between bleeding and stimulation. It is often applied before de-hiding (up to 10 min after bleeding) in compliance with the time constraint. The initial cost is very low and it is safer in the work place. The major demerit of LVES is that it is labor intensive since the electrode needs to be manually applied. Although, LVES is safer, its consistency in effect is lesser than HVES (500-1,000 V or more) (Bendall, 1980; Bouton et al., 1980). High voltage electrical stimulation gives room for longer delay time between bleeding and stimulation (up to $60 \mathrm{~min}$ after exsanguination). However, it requires huge capital outlay and adequate precaution needs to be taken to ensure the safety of workers. Hwang and Thompson (2001) reported that irrespective of the type of voltage used, when ES is applied to a carcass at about 3 min postmortem, its tenderizing effect would be relatively less than when it is applied at about 40 min postmortem. The authors attributed this to the initial reduction in calpain activity immediately after slaughter. Contrarily, Bendall (1976) suggested that the response of bovine to ES decreases significantly after 50 min postmortem and sooner for lamb carcass. The authors concluded that it is ideal to carry out ES at about $30 \mathrm{~min}$ after bleeding. However, in recent time, carcasses are often subject to ES immediately after postmortem. This has been reported to aid bleeding and enhance meat tenderness (MLA and AMPC, 2011).

Mckeith et al. (1981) compared the effectiveness of HVES and LVES at different periods using a total of 390 calves and young bullocks. Carcasses were stimulated at 5 min after exsanguination, 20 and $30 \mathrm{~min}$ after evisceration. Carcasses were subjected to $550 \mathrm{~V}$ or $150 \mathrm{~V}$ for 1 or $2 \mathrm{~min}$ at $16 \mathrm{pulses} / \mathrm{min}$ and compared against non-stimulated ones and the impulses took place for $1.8 \mathrm{~s}$ with an interval of 1.8 $\mathrm{s}$ between them. The result showed no improvement for flavor when ES was applied for 1 or 2 min. Nevertheless, carcasses stimulated with $550 \mathrm{~V}$ had more tender, brightly colored, better flavored and leaner meat than those stimulated with $150 \mathrm{~V}$. It was concluded that HVES $(550 \mathrm{~V})$ and short time $(1 \mathrm{~min})$ is ideal for improvement of meat palatability. The report of Roeber et al. (2000) revealed that duration and voltage intensity of ES affected beef color and tenderness. The right halves of beef carcasses were stimulated while the left halves were non-stimulated. High voltage (HV) $(300 \mathrm{~V})$ was compared against medium voltage (MV) $(100 \mathrm{~V})$. High duration (HD) (16 cps) and medium duration (MD) (11 cps) at $60 \mathrm{~Hz}$ were also compared. The result showed that all ES treatments yielded more tender and brighter colored beef than non-stimulated 
sides. For carcasses whose non-stimulated sides had Warner-Bratzler Shear (WBS) values higher than $4.5 \mathrm{~kg}$, corresponding sides treated with HVHD, HVMD, MVHD, and MVMD had shear force values less than $4.5 \mathrm{~kg}$ at $60 \%$, $75 \%, 88 \%$, and $50 \%$ of the time, respectively. Morton and Newbold (1982) reported that time taken for postmortem ATP to decline to half of the initial control in sheep was about $20 \mathrm{~min}, 2$ to $3 \mathrm{~h}$ and 5 to $6 \mathrm{~h}$ in the HVES $(240 \mathrm{~V}$, $\left.14.3 \mathrm{~s}^{-1}, 10 \mathrm{~ms}, 50 \mathrm{~Hz}\right)$, LVES $\left(45 \mathrm{~V}, 14.3 \mathrm{~s}^{-1}, 10 \mathrm{~ms}, 50 \mathrm{~Hz}\right)$ and the control carcasses, respectively.

\section{Practical application of ES}

Recently, ES is often used for other purposes in addition to meat quality improvement. In some abattoirs especially in Australia and New Zealand, ES is applied immediately after stunning before slaughtering, immediately after slaughter and/ or during de-hiding. When applied after stunning prior slaughtering, it is aimed at ensuring occupational health (workers' safety) to prevent shaking of the hind legs when the animal is being exsanguinated. Electrical stimulation applied immediately after slaughter is aimed at increasing the efficiency of bleeding out and to promote blood collection (Craig et al., 1999; MLA and AMPC, 2011). This procedure has been reported to enhance tenderness because the low voltage ES reduces muscle ATP, making it unavailable for muscle contraction during cold storage. In addition, depletion of ATP by ES could lower the frozen storage time necessary to deplete ATP. When applied during de-hiding (especially when a downward hide puller is used) it is aimed at stiffening the animal's backbone to prevent breakage of spinal cord (MLA and AMPC, 2011). However, it is recommended to reduce all forms of ES on carcasses to prevent heat toughening which could occur during pre-rigor due to rapid decline in muscle $\mathrm{pH}$ while muscle temperature is still high (MLA and AMPC, 2011).

In evaluating the efficacy of $\mathrm{ES}$, it is necessary to realize that concurrently with the need to improve meat quality and the efficiency of abattoir operations, there is increasing propensity for abattoirs to engage in integrated preparation of prepackaged cuts (Lawrie and Ledward, 2006). This is due to the rapidly changing consumption patterns that necessitate individual smaller cuts. In addition, hot carcass deboning followed by vacuum packaging of the warm cuts further substantiates the propensities all of which lower exudative and evaporative losses. Given the relatively small proportions of individual cuts, it might be useful to electrically stimulate the cuts or whole carcass to avoid cold shortening since the former would readily be induced under the high rate of cooling accompanying them. Rapid cooling of carcass lowers microbial proliferation, which could occur especially in individual cuts having large surface to volume ratio. Although, cold shortening is prevented, these conditions could avert the tenderizing effect of ES by creating conditions (in vivo temperature and low $\mathrm{pH}$ ) favorable for quick conditioning. The aforementioned problem could be solved by subjecting various joints or cuts to different cooling regimes following their removal from hot carcass. However, this is somewhat complicated considering the complex nature of muscles and variation in their response to ES and conditioning processes. Different muscles in carcass differ in their rate of cooling. Muscles close to the surface of carcass chill quickly since they have low depth. Conversely, deep muscles situated in the centre of carcass chill more slowly. Thus, it can be inferred that efficacy of ES depends on the nature and duration of cold storage after stimulation. This corroborates the report of Wiklund et al. (2001) who studied the effect of ES on red venison. Their result indicated that through the prevention of cold shortening, ES improved the tenderness of stimulated carcasses compared to non-stimulated ones. However, the tenderizing effect of ES was lost during subsequent ageing at $-1.5^{\circ} \mathrm{C}$. This implied that ES is not beneficial for products stored for long term at chill temperature.

In some tropical countries, hot deboning could expose the meat to a temperature of $30^{\circ} \mathrm{C}$ to $40^{\circ} \mathrm{C}$. Under this condition, during the onset of rigor mortis, early muscle excision could cause contraction and toughening (Locker et al., 1985). Thus, assessing the effect of ES in such situations will be of prime interest. Babiker and Lawrie (1983) reported that when exposed to temperature of $30^{\circ} \mathrm{C}$ to $40^{\circ} \mathrm{C}$, bovine Longissimus dorsi M. exhibited pronounced tenderness compared to non-stimulated ones. However, at $40^{\circ} \mathrm{C}$ and in contrast to the observations at $30^{\circ} \mathrm{C}$, there was intense loss of water holding capacity accompanied with marked microbial proliferation; besides, the tenderness of electrically stimulated samples decrease proportionately. This observation inferred that the favorable effects of high temperature in enhancing proteolysis were overshadowed by increased protein degradation of the enzymes responsible for the breakdown of proteins.

\section{Role of ES on postmortem glycolysis}

The mode of action of ES lies on its ability to accelerate postmortem glycolysis resulting in $\mathrm{pH}$ decline via rapid depletion of muscle glycogen (Hwang et al., 2003; Simmons et al., 2008; Castigliego et al., 2012). The application of ES results in extensive contraction of skeletal muscles whereby, the fibers become extended preventing additional contraction thus preventing shortening (Simmons et al., 2008; Mota-Rojas et al., 2012). Besides, myofibrillar matrix is physically disrupted thus accelerating proteolysis (Hwang et al., 2003). Two crucial postmortem changes accelerated by ES are the onset of rigor mortis by acceleration of the rate of glycolysis and $\mathrm{pH}$ decline to values less than 6.4. On applying $\mathrm{ES}$, the rate of the 
aforementioned processes increases significantly but decreases on its cessation (Bendall, 1980). Furthermore, ES precludes thaw rigor in hot carcass frozen prior the onset of rigor mortis and rigor resolution. Based on this, the major merit of ES is the prevention of cold shortening that could arise during postmortem refrigeration due to a swift decline in temperature. Cross (1979) identified several factors that could be responsible for the tenderizing effect of ES. These include the accelerated depletion of ATP, which results in the prevention of cold shortening and rapid decline in postmortem muscle $\mathrm{pH}$ amidst high muscle temperature $\left(30^{\circ} \mathrm{C}\right.$ to $32^{\circ} \mathrm{C}$ ) which enhances the activity of proteolytic enzymes or degradation of muscle fibers.

\section{The biochemical and physiological basis of ES}

Electrical stimulation accelerates postmortem glycolysis resulting in a $\mathrm{pH}$ decline via rapid depletion of muscle glycogen (Hwang et al., 2003; Simmons et al., 2008; Castigliego et al., 2012). Physiologically, the mechanisms of action of ES for improving meat tenderness occur by the release of calcium ion $\left(\mathrm{Ca}^{2+}\right)$ from sarcoplasmic reticulum (calcium ion pump). Muscle contraction is promoted by the activation of myosin-ATPase. During muscle contraction, the liberated $\mathrm{Ca}^{2+}$ activates calpain and disrupts the Z-line (Warris, 2010; Mota-Rojas et al., 2012). During this event, the muscle $\mathrm{pH}$ and temperature is about $6.5^{\circ} \mathrm{C}$ and $30^{\circ} \mathrm{C}$, respectively (Warris, 2010; Mota-Rojas et al., 2012). This condition favors intense calpain activity. There is also the disruption of lysosomes resulting in the release of cathepsins, which enhance muscle proteolysis (Soria and Corva, 2004; Warris, 2010). On the other hand, when cold shortening occurs that is when hot carcasses are subjected to cold storage $\left(10^{\circ} \mathrm{C}\right.$ to $\left.15^{\circ} \mathrm{C}\right)$ prior the dissipation of body heat, the calcium ion pump is disrupted giving room for massive liberation of $\mathrm{Ca}^{2+}$ from the sarcoplasm amidst the activeness of the myosin-ATPase. Concurrently, the concentration of ATP in muscle is very high thus providing energy needed for contraction. This gives room for severe muscle contraction leading to meat toughening (Warris, 2010). The severity of toughness increases when thaw-rigor occurred. This takes place when pre-rigor meat is subjected to freezing temperature $\left(<-10^{\circ} \mathrm{C}\right)$ (Lawrie and Ledward, 2006). Under this condition, ATP has not been depleted; despite the disruption of calcium ion pump by freezing, the $\mathrm{Ca}^{2+}$ remains in the sarcoplasm. Thus, when such meat is thawed in the presence of high concentration of ATP, severe muscle contraction, which leads to shortening takes place. It is therefore not surprising that in countries like Australia and New Zealand where the common practice is to subject carcasses to low voltage electrical stimulation immediately after exsanguination yields tender meat. This is because the low voltage ES employed depletes muscle ATP, which otherwise would have been used for muscle contraction.
Besides, ES could decrease the frozen storage time necessary to deplete ATP. Lawrie and Ledward (2006) reported that during thaw rigor, an excised muscle could undergo shortening up to $30 \%$ of its original length. Nevertheless, because of the attachment of muscle to the skeleton, its shortening may be prevented to some extent.

The presence of ATP allows the polymerization of contractile protein from actin and myosin to actomyosin during muscle contraction. Reduction in sarcomere length, which subsequently leads to muscle toughening, is a good indicator of protein polymerization. During the onset of rigor mortis, depletion of adenosine triphosphate (ATP) to adenosine diphosphate (ADP) occurs. ADP further depletes to ionosinmonophosphate (IMP) (Savell et al., 2005). This chemical pathway is incapacitated to provide energy needed for polymerization. Thus, rigor mortis takes place when there is a full conversion of ATP to IMP (Prandl et al., 1994). Electrical stimulation ensures full depletion of ATP to IMP. Therefore, there is no available energy for protein polymerization and this prevents muscle contraction. Under this condition, meat tenderness is not affected by freezing since further polymerization cannot occur (Savell et al., 2005). Kang et al. (1991) while studying the effect of ES (50 $\mathrm{mA})$ in rabbit muscle, reported the polymerization of actin and myosin to form actomyosin complex during contraction. Alterations in myofibrillar proteins were evident. The authors reported that the actomyosin complex is pulled in the direction of meromyosin fraction of the main myosin helix. Nevertheless, ATPase activity is present in meromyosin. The actomyosin complex breaks down into actin and myosin when the complex reaches the meromysin ATPase region. This phenomenon leads to relaxation of muscles. Furthermore, an initial decrease in ATPase activity was reported in ES meat but increased slowly during the $7 \mathrm{~d}$ postmortem storage. The authors concluded that changes in actomyosin were minimized by ES.

\section{Variations in response of muscles to electrical stimulation}

Muscles differ biochemically. Therefore, their response to cold shortening and conditioning behavior differ. These differences result from inherent differences in muscle fibers, which make up the muscle. Muscle fibers differ in size, densities and physiological and biochemical properties; hence, the variation between and within muscles. Color differences (white and red) between muscle fibers has been used as the basis for classification and elucidating characteristics exhibited by each muscle. However, it has been recognized that muscle fibers are not conspicuously white or red but are a heterogeneous mix of the two. The heterogeneous nature of muscle substantiates the variation and complexity in their response to ES. This could be responsible for the conflict of reports on the efficacy of ES 
on meat quality improvement. Lawrie and Ledward (2006) reported that the rate at which inorganic phosphate was produced during postmortem glycolysis was substantially higher in white muscle than in red muscle. Hence, in early postmortem, the attainment of relatively high concentration of inorganic phosphate in white muscle could explain its' lack of cold shortening. Furthermore, Buege and Marsh (1975) reported that pre-rigor red muscles did not exhibit cold shortening when cooled below $15^{\circ} \mathrm{C}$ provided they are supplied with adequate oxygen. This resistance is terminated by reagents that prevent the usage of oxygen for resynthesis of ATP. The authors concluded that the liberation of $\mathrm{Ca}^{2+}$ in postmortem anaerobic condition and the failure of the sarcotubular system to efficiently reabsorb the $\mathrm{Ca}^{2+}$ at low temperatures were responsible for cold shortening.

One of the modes of action of ES in the improvement of tenderness is avoidance of cold shortening (Cross, 1979; Bouton et al., 1980; Mota-Rojas et al., 2012). Thus, 'white' muscles, which are less affected by cold shortening, are greatly influenced by ES while ES has less affect 'red' muscles due to their relative susceptibility to cold shortening (Devine et al., 1984). The difference in muscle response to ES could give a clue to the absence of marked exudation in beef as oppose to an intense loss of water holding capacity in PSE pork at low $\mathrm{pH}$ and in vivo temperature. Although, den Hertog-Meischke et al. (1997) reported reduction in water holding capacity in beef due to rapid $\mathrm{pH}$ decline, the magnitude of decrease in water holding capacity depends on the rate of chilling. It is possible that the rapid fall in $\mathrm{pH}$ caused by ES promoted intracellular osmotic pressure to a sufficient level to permit loss of water-holding capacity by the muscle proteins in pork. This corroborates the view of Henderson et al. (1970) that pork generally undergoes greater conditioning alterations than beef and this could raise its'cellular osmotic pressure more than that of beef. It is possible that pork proteins (white muscle) are inherently more susceptible to denaturation than beef muscles (red muscles). Evidence abounds that at post-mortem, white muscles are more readily denatured than red muscles (Lawrie and Ledward, 2006). In addition, George et al. (1980) reported that the sarcolemma of pork muscle is more permeable to water than that of beef. This could further account for the 4-5 fold increase in exudation observed in pork muscle subjected to ES when compared with non stimulated sides as reported by Gigiel and James (1984).

\section{The influence of ES on meat eating quality}

Meat eating quality is largely determined by sensory properties. Inability to meet consumers' expectation with respect to sensory traits would lead to economic loss on the part of the producer. Sensory attributes of meat are influenced by myriad factors that occur at pre and post slaughter stages. Alteration of these factors could further promote quality attributes. Electrical stimulation is one of the approaches for enhancing the sensory characteristics of meat. The effects of ES on meat quality characteristics are highlighted below:

Color: Color plays vital role in influencing consumer acceptability of meat. It is the first quality characteristic that consumers consider and thus act as a powerful tool for selection and identification of meat. It is a good quality indicator of freshness or otherwise of meat. In addition to tenderness, ES has been reported to improve meat color in pork (Taylor and Martoccia, 1995), lambs (Polidori et al., 1999), beef (Mckenna et al., 2003), venison (Wiklund et al., 2001), chevon (Savell et al., 1977; Cetin and Topcu, 2009) and chickens (Birkhold and Sams, 1993; Young et al., 1999). The ability of ES to improve meat color could be due to its capability to reduce metabolites of surviving oxidative pathways in the muscle (Lawrie and Ledward, 2006). It could also result from a fast drop in $\mathrm{pH}$, which causes myofibrillar proteins in the ES carcass to reach their isoelectric point earlier thereby opening up the structure of myofibrillar proteins thus causing the oxidation of myoglobin. This may be responsible for the fast development of brighter color in electrically stimulated than in non-stimulated meat when bloomed for about 12 to $20 \mathrm{~h}$ postmortem. However, when muscles are exposed to the atmosphere for about 48 to $72 \mathrm{~h}$ postmortem, the difference in color development is not obvious (Lawrie and Ledward, 2006). This occurred because by this time, ultimate $\mathrm{pH}$ would have been reached by both electrically stimulated and non-stimulated meat. The myofibrillar proteins of both meat samples would have opened up and the rate of myoglobin oxidation would proceed in the same manner (Lawrie and Ledward, 2006).

Studies conducted by Young et al. (1999) to investigate the effects of ES on color alterations in 96 chicken carcasses showed that ES promoted brighter color but less redness intensity of the Pectoralis major M. accompanied by a rapid decline in $\mathrm{pH}$. The $\mathrm{pH}$ of the non-stimulated samples decline to a similar level as that of stimulated samples after $2 \mathrm{~h}$ postmortem. This finding corroborates the report of Warris (2010) which stated that the bright color exhibited by electrically stimulated carcass could be due to rapid acidification of muscle caused by denaturation of protein which resulted in higher light reflectance on the surface of meat. In cattle, Nazli et al. (2010) reported that when high voltage (500 to $800 \mathrm{~V}$ ) electrical stimulation was applied to bovine carcasses, there was a rapid $\mathrm{pH}$ decrease coupled with brighter meat color compared to beef carcasses that were not stimulated. Roeber et al. (2000) reported positive influence of ES on beef color, which resulted from decreased time for carcass ripening. The 
works of Sleper et al. (1983) and Martin et al. (1983) also showed improvements in colour of bovine muscles when subjected to ES. Conversely, Ledward et al. (1986) reported that electrically stimulated bovine Semimembranosus M. exhibited pronounced formation of metmyoglobin, which resulted in color loss. This observation corroborates the report of Hector et al. (1992) which showed that low voltage ES causes $\mathrm{pH}$ decrease $(<6)$ in beef which in combination with in vivo temperature was responsible for color loss and this was partly due to myosin denaturation. In sheep, high voltage electrical stimulation increased the yellowness and lightness of Longissimus thoracis M. as well as the redness and yellowness in the Gluteus medius M. of lambs (King et al., 2004). A brighter or more youthful color was observed in electrically stimulated lamb carcasses as compared to non-stimulated ones (Riley et al., 1981; Kerth et al., 1999).

Tenderness: The primary aim of electrical stimulation is to enhance meat tenderness (Aalhus et al., 1994; Simmons et al., 2008; Kemp et al., 2010). Tenderness is the most variable and important meat eating quality parameter. Electrical stimulation has been used extensively to enhance tenderness as well as general meat quality traits (Pospiech, 2003; Warris, 2010). There is no consensus among researchers on how ES is associated with tenderness. Some authors attributed the tenderizing effect of ES to avoidance of cold shortening (Cross, 1979; Bouton et al., 1980; MotaRojas et al., 2012) while others opined that it could be due to rapid and intense conditioning alterations resulting from the agglomeration of in vivo temperature and low $\mathrm{pH}$ (Bendal, 1980; Dutson et al., 1982). Savell et al. (1977) and Dutson (1980) suggested that when ES is applied, the release of $\mathrm{Ca}^{2+}$ from the calcium ion pump could promote proteolysis by the calpain. In addition, cathepsins may be released due to the disruption of the lysosomes membrane following continuous decline in $\mathrm{pH}$ (Dutson et al., 1980; Locker, 1985). Lawrie and Ledward, (2006) further inferred that the observed tenderness in electrically stimulated meat as a factor additional to the prevention of cold shortening could be due to accelerated proteolysis at in vivo temperatures.

In the absence of ES, ultimate $\mathrm{pH}$ is reached at about 10 to $12 \mathrm{~h}$ postmortem in pigs and ruminants whereas with ES this value could be attained within 1 to $2 \mathrm{~h}$ postmortem. ES meat displays severe muscular contractions, which result in a quick rate of glycolysis and $\mathrm{pH}$ decline. Nevertheless, this rapid decline in $\mathrm{pH}$ impels the occurrence of early rigor mortis, which in turn induce rapid rigor resolution that enhances a fast rate of relaxation (Soria and Corva, 2004; Warris, 2010). Simultaneously, there is rapid liberation of intracellular calcium leading to increased calpain activity as well as increased rate of proteolysis thus enhancing meat tenderness (Elgasim et al., 1981; Ducastaing et al., 1985).
Pospiech et al. (2003) reported that the degradation of protein during ripening is responsible for meat tenderness. This according to Hedrick et al. (1994) and Ducastaing et al. (1985), results from behavioral changes in muscle fiber, which can be explained by three major events. Firstly, the impediment of cold shortening by reduction of slow phase of rigor mortis. Secondly, the liberation of calcium by ES, which induces increased calpain activity that causes myofibrillar proteolysis and lastly, the electric current causes severe contractions, which fractures the myofibril. The tenderizing effect of ES as reported by Cross (1979), Honikel et al. (1983) and Davey and Gilbert (1980) could have resulted from the prevention of cold shortening caused by rapid depletion of ATP; rapid $\mathrm{pH}$ decline amidst high muscle temperature, which favors increased activity of proteolytic enzymes; physical disruption of muscle fibers. The use of mechanical technique and enzymes in conjunction with ES could also improve meat tenderness by reducing the ripening time as well as produce more tender and brighter colored meat (Yanar and Yetim, 2003). The need to enhance various sensory properties of meat necessitates ripening. Application of ES reduces the ripening time thus enhancing meat quality. The extent of weakening and alterations of myofibrillar proteins determines the ultimate meat tenderness. Takahashi et al. (1987) suggested that tenderizing effect of ES is due to physical damage resulting from tetanizing contractions. The avoidance of cold shortening by ES could be due to nonenzymatic disruption of myofibrillar proteins (Takahashi, 1992) mediated by lysosomal enzymes (Dutson et al., 1980). There is possibility that the tenderizing effect of ES could be modulated by agglomeration of two or more underlying mechanisms.

Structurally, meat is composed of connective tissue and myofibrillar proteins (Warris, 2010). The protein content of the connective tissue varies depending on various factors, which include but not limited to specific muscle activity, animal species, age of animal, muscle type etc. (Pospiech, 2003). Trial conducted by Solomon et al. (1986) revealed that young bovine carcasses when subjected to ES at $1.5 \mathrm{~A}$, $550 \mathrm{~V}$ and 20 pulses for $2 \mathrm{~s}$ produced more tender meat than non-stimulated carcasses as evaluated by sensory panels. In contrast, Kim et al. (2013) reported that low voltage ES at $90 \mathrm{~min}$ after exsanguination had no effect on tenderness development and proteolysis in bovine gracilis M., Longissimus dorsi M. and semimembranosus M. Similarly, studies conducted by Botha et al. (2009) inferred that low voltage ES offered no improvement in the quality attributes of ostrich. Using twenty-two ovine carcasses from castrated Doper weighing 40 to $50 \mathrm{~kg}$, Davel et al. (2003) investigated the influence of electrical stimulation at $20 \mathrm{~V}$, $45 \mathrm{~Hz}$ for $45 \mathrm{~s}$ on sensory features of mutton. Following, stimulation, carcasses were chilled at $2^{\circ} \mathrm{C}$ for $24 \mathrm{~h}$. Prior 
sensory evaluation, Longissimus lumborum and thoracis $\mathrm{M}$. were removed, cut into two, packaged under vacuum and subjected to frozen storage at $-30^{\circ} \mathrm{C}$. Thereafter, the right half was grilled at $160^{\circ} \mathrm{C}$ at internal temperature of $73^{\circ} \mathrm{C}$. The result revealed that the acceptability of stimulated samples was higher than non-stimulated samples. However, no effect of ES was found on cooking losses related to slaughter weight and carcass fat.

Studies conducted by Guerrero et al. (2004) showed that varying stimulation voltages and times influenced $\mathrm{pH}$ of Longissimus dorsi M. of female alpacas. Two voltages (500 $\mathrm{V}$ and $600 \mathrm{~V}$ ) were applied for two periods (30 s and $60 \mathrm{~s}$ ) and $\mathrm{pH}$ was monitored after 1 to $24 \mathrm{~h}$ postmortem. A significant difference in $\mathrm{pH}$ was observed between the treated and control meat samples. It was reported that $500 \mathrm{~V}$ applied for $30 \mathrm{~s}$ caused a rapid decline in $\mathrm{pH}$ (5.27) compared to the control, which had $\mathrm{pH}$ (6.31) after $24 \mathrm{~h}$ postmortem. Electrically stimulated meat in general had $\mathrm{pH}<6.0$ while untreated meat had $\mathrm{pH}>6.0$. This observation, according to the authors, could have resulted from amplification of the rate of muscle contraction cycles. This accelerates the depletion of glucose stores and enhanced the production of lactate. Also, there was decline in postmortem muscle $\mathrm{pH}$ when carcasses obtained from calves were electrically stimulated and this was explained by accumulation of lactate from glycolysis lowering the $\mathrm{pH}$ to 6.56 and 5.48 after 2 and $24 \mathrm{~h}$ postmortem, respectively (Bryne et al., 2000).

Electrical stimulation of carcasses obtained from electrically stunned birds has been shown to affect $\mathrm{pH}$ decline, blood loss and increase in sarcomere length (Craig et al., 1999). When subjected to $440 \mathrm{~V}$, the onset of rigor mortis was accelerated. This report is in line with the earlier report of Savell et al. (1977) with respect to sarcomere length. Canstaneda et al. (2005) investigated the effect of ES on broiler meat. Fifty-four (54) female broilers weighing 1.5 to $1.6 \mathrm{~kg}$ were subjected to ES at $450 \mathrm{~mA}, 450 \mathrm{~V}, 2 \times 2 \mathrm{~s}$, 7 pulse/s. The results indicated that ES enhances meat tenderness because of the rapid loss of ATP, $\mathrm{pH}$ decline and physical disruption of muscle fiber. It was further reported that rapid cooling of carcass at $4^{\circ} \mathrm{C}$ did not affect the functionality of protein hence PSE condition was not observed. However, the negative impact of slow cooling after ES was evident in various studies. The findings of Elgasim et al. (1981) showed that slow cooling after ES produced a normal $\mathrm{pH}$ (5.9) in meat but with PSE features. Slow cooling could also predispose carcass to pale coloring and reduction in water holding capacity (Mota-Rojas et al., 2012). Zywica and Banach (2003) studied the effect of ES and sex on meat tenderness. The authors used 18-month bulls and heifer and the carcasses were split longitudinally into two halves. The right half served as the control while the left half was subjected to ES of $17 \mathrm{~Hz}, 330 \mathrm{~V}$ and 0.9 pulses for $120 \mathrm{~s}$. Instrumental and sensory analysis of Hemiaponeurotic $M$. revealed that sex of animals influenced the effect of ES on cooked meat. From their trial, ES heifer carcasses produced a better meat quality. Reports of Locker (1985) and Chrystall and Devine (1985) showed that electrically stimulated beef was rated as $10 \%$ to $50 \%$ more tender than non-stimulated ones. While investigating the effect of diet type on efficacy of ES, Smith (1985) asserted that sometimes, ES was more effective in grass-fed animals and animals fed grains for a short period than animals fed grains for a long period. He also reported that the efficacy of ES was higher in lower-grade carcasses than higher-grade carcasses.

Juiciness: There are variable reports on the effect of ES on meat juiciness. Some authors reported that ES enhanced beef juiciness (Hwang and Thompson, 2001). However, Ferguson et al. (2000) reported a decrease in juiciness while Jeremiah and Martin (1981) reported no effect. The discrepancies in these reports according to Juarez et al. (2012) could be due to the degree of physical disruption of muscle fiber, the degree to which ultimate $\mathrm{pH}$ is affected by ES and the degree to which ES accelerates proteolytic activity. Furthermore, juiciness perception in electrically stimulated meat may be influenced by back fat thickness as well as the amount of intramuscular fat (Juarez et al., 2012). Rapid decline in $\mathrm{pH}$ during $\mathrm{ES}$ in conjunction with insulating properties of fat could cause decline in water holding capacity and additional degradation of myofibrillar proteins. This corroborates the findings of Ferguson et al. (2000) that showed profound decrease in juiciness of ES meat from feedlot finished cattle compared to ES meat from pasture-finished cattle.

\section{Meat microbiological quality}

Food safety is a major concern in the meat industry especially when intervention is applied. Various studies have been conducted on the microbial stability of ES meat. Studies conducted by Guerrero et al. (2004) showed a lower bacterial count in ES meat compared to the control. The authors asserted that the decrease in bacterial load resulted from high content of lactic acid, which brought about rapid decline in $\mathrm{pH}$, which caused unfavorable conditions for microbial proliferation. However, the $\mathrm{pH}$ is only bacteriostatic (inactivate microbial activity) but not bactericidal (kill microbes). Ockerman and Szczawinski (1983) reported that ES reduced initial postmortem $\mathrm{pH}$ and aerobic plate count of beef tissue inoculated with mixed microflora. However, the microbial count increased significantly during the aerobic product storage at 0 to $2^{\circ} \mathrm{C}$ up to two weeks. Similarly, Butler et al. (1981) studied pH and microbial populations in ground meat obtained from bovine Infraspinatus and Biceps femoris $\mathrm{M}$. The meat were hitherto inoculated with Pseudomonas spp, Moraxella spp, 
Lactobacillus spp, Brochothrix thermosphaca, Acinetobacter spp and Erwinia herbicola and subjected to $\mathrm{ES}$ at $550 \mathrm{~V}$ and 16 pulses at interval of $1.8 \mathrm{~s}$. Both inoculated and non-inoculated meat samples with or without ES were assessed for the same microbial populations. The authors reported $\mathrm{pH}$ decrease in ES samples but a significant difference was not found between stimulated and non-stimulated samples.

Ockerman and Szczawinski (1984b) reported that ES did not reduce bacterial counts for non-heated microorganisms but caused an initial decrease in post mortem $\mathrm{pH}$ in pork. They further reported that ES slightly reduced the thermo-resistance of Pseudomonas putrefaciens and Lactobacillus plantarum but did not reduce thermoresistance of Streptococcus faecalis. The relationships among ES, hot or cold deboning, beef cuts, and bacteria counts were studied by Kotula and Emswiler-Rose (1981). The authors concluded that ES and cold or hot deboning did not affect proliferation of aerobic bacteria. Ockerman and Szczawinski (1984a) also studied synergistic effect of ES and meat processing methods on meat microbial stability; no synergistic effect was found between ES and storage at $-21^{\circ} \mathrm{C}$, between ES and $3 \%$ salt and between ES and $3 \%$ salt+200 ppm nitrate. However, synergistic effect was found between ES and heating at $60^{\circ} \mathrm{C}$. The author also opined that lowered $\mathrm{pH}$ was not responsible for decrease in thermoresistance caused by ES.

\section{CONCLUSION}

Myriad studies have shown that ES is an effective technique for enhancing various meat quality traits particularly meat tenderness. Nevertheless, the success of the technique is premised on several multifaceted factors that cut across antemortem, perimortem and postmortem phases of an animal. The core attribute of ES is its ability to hasten postmortem glycolysis. ES accelerates the onset as well as resolution of rigor thus reducing processing time and labor. Electrical stimulation also gives room for other processes to be carried out just immediately after bleeding and cleaning.

\section{REFERENCES}

Aalhus, J., S. Jones, D. Best, W. Robertson, and S. Lutz. 1994. The efficacy of high and low voltage electrical stimulation under different chilling regimes. Can. J. Anim. Sci. 74:433-442.

Babiker, S. and R. Lawrie 1983. Post-mortem electrical stimulation and high temperature ageing of hot-deboned beef. Meat Sci. 8:1-20.

Bendall, J. R. 1980. The electrical stimulation of carcasses of meat animals. In: Developments in Meat Science (Ed. R. A. Lawrie). Applied Science, Barking, pp. 37-59.

Bendall, J. R., C. C. Ketteridge, and A. R. George. 1976. The electrical stimulation of beef carcasses. J. Sci. Food Agric. 27:1123-1131.

Birkhold, S. and A. Sams. 1993. Fragmentation, tenderness, and post-mortem metabolism of early-harvested broiler breast fillets from carcasses treated with electrical stimulation and muscle tensioning. Poult. Sci. 72:577-582.

Botha, S., S. van Schalkwyk, S. Cloete, and L. Hoffman. 2009. Effect of bleeding method and low voltage electrical stimulation on meat quality of ostriches. S. Afr. J. Anim. Sci. 39:206-213.

Bouton, P., A. Ford, P. Harris, and F. Shaw. 1980. Electrical stimulation of beef sides. Meat Sci. 4:145-155.

Buege, D. and B. Marsh. 1975. Mitochondrial calcium and postmortem muscle shortening. Biochem. Biophys. Res. Comm. 65:478-482.

Butler, J., G. Smith, J. Savell, and C.Vanderzant. 1981. Bacterial growth in ground beef prepared from electrically stimulated and non-stimulated muscles. Appl. Environ. Microbiol. 41(4): 915-918.

Bryne, C., D. Troy, and D. Buckley. 2000. Postmortem changes in muscle electrical properties of bovine $\mathrm{m}$. longissimus dorsi and their relationship to meat quality attributes and $\mathrm{pH}$ fall. Meat Sci. 54:23-34.

Castaneda, M., E. Hirschler, and A. Sams. 2005. Research note: Functionality of electrically stimulated broiler breast meat. Poult. Sci. 84:479-481.

Castigliego, I., A. Armani, and A. Guidi. 2012. Meat color. In: Handbook of Meat and Meat Processing. 2nd ed. (Ed. Y. H. Hui) CRC. pp. 81-92.

Cetin, O. and T. Topcu. 2009. Effects of electrical stimulation on meat quality in goat carcasses. J. Food. Agric. Environ. 7 (3-4), 101-105.

Chrystall, B. and C. Devine. 1985. Electrical stimulation: Its early development in New Zealand. Adv. Meat Res. Springer. pp. 73-119.

Craig, E., D. Fletcher, and P. Papinaho. 1999. The effects of antemortem electrical stunning and postmortem electrical stimulation on biochemical and textural properties of broiler breast meat. Poult. Sci. 78:490-494.

Cross, H. 1979. Effects of electrical stimulation on meat tissue and muscle properties-a review. J. Food Sci. 44:509-514.

Davel, M., M. Bosman, and E. Webb. 2003. Effect of electrical stimulation of carcasses from Dorper sheep with two permanent incisors on the consumer acceptance of mutton. S. Afr. J. Anim. Sci. 33:206-212.

Davey, C. L. and K. V. Gilbert. 1975. Cold shortening capacity and beef muscle growth. J. Sci. Food Agric. 26:755-760.

den Hertog-Meischke, M., F. Smulders, J. Van Logtestijn, and F. Van Knapen. 1997. The effect of electrical stimulation on the water-holding, capacity and protein denaturation of two bovine muscles. J. Anim. Sci. 75:118-124.

Devine, C. E., S. Ellery, and S. Averill.1984. Responses of different types of ox muscle to electrical stimulation. Meat Sci. 10:35-51.

Ducastaing, A., C. Valin, J. Schollmeyer, and R. Cross. 1985. Effects of electrical stimulation on post-mortem changes in the activities of two $\mathrm{Ca}$ dependent neutral proteinases and their inhibitor in beef muscle. Meat Sci. 15:193-202.

Dutson, T. R., G. C. Smith, and Z. Carpenter. 1980. Lysosomal 
enzyme distribution in electrically stimulated ovine muscle. J. Food Sci. 45:1097-1098.

Dutson, T. R., J. W. Savell, and G. C. Smith. 1982. Electrical stimulation of ante-mortem stressed beef. Meat Sci. 6:159-162.

Elgasim, E., W. Kennick, L. McGill, D. Rock, and A. Soeldner. 1981. Effects of electrical stimulation and delayed chilling of beef carcasses on carcass and meat characteristics. J. Food Sci. 46:340-343.

Ferguson, D. M., S. Jiang, H. Hearnshaw, S. R. Rymill, and J. M. Thompson. 2000. Effect of electrical stimulation on protease activity and tenderness of $\mathrm{m}$. longissimus from cattle with different proportions of Bos indicus content. Meat Sci. 55: 265-272.

George, A., J. Bendall, and R. Jones. 1980. The tenderizing effect of electrical stimulation of beef carcasses. Meat Sci. 4:51-68.

Gigiel, A. J. and S. J. James. 1984. Electrical stimulation and ultrarapid chilling of pork. Meat Sci. 11:1-12.

Guerrero, O., M. Vilca, and D. Ramos. 2004. Estimulación eléctrica de canales de alpacas para mejorar su calidad organoléptica. Rev. Invest. Vet. Perú. 15:151-156.

Harsham, A. and F. E. Deatherage. 1951. Tenderization of meat. U.S. Patent 2544681.

Hector, D. A., C. Brew-Graves, N. Hassen, and D. A. Ledward. 1992. Relationship between myosin denaturation and the colour of low-voltage-electrically-stimulated beef. Meat Sci. 31:299-307.

Hedrick, H., E. Aberle, J. Forrest, M. Judge, and R. Merkel. 1994. Properties of fresh meat. Principles of Meat Science. Kendall Hunt. pp. 3-289.

Henderson, D., D. E. Goll, and M. Stromer. 1970. A comparison of shortening and $\mathrm{Z}$ line degradation in post-mortem bovine, porcine, and rabbit muscle. Am. J. Anat. 128:117-135.

Honikel, K., P. Roncales, and R. Hamm. 1983. The influence of temperature on shortening and rigor onset in beef muscle. Meat Sci. 8:221-241.

Hwang, I., C. Devine, and D. Hopkins. 2003. The biochemical and physical effects of electrical stimulation on beef and sheep meat tenderness. Meat Sci. 65:677-691.

Hwang, I. and J. Thompson. 2001. The effect of time and type of electrical stimulation on the calpain system and meat tenderness in beef longissimus dorsi muscle. Meat Sci. 58: 135-144.

Jeremiah, L. and A. Martin. 1981. The effect of electrical stimulation on the palatability and consumer acceptance of boneless rib steaks. J. Food Qual. 4:165-173.

Juarez, M., N. Aldai, O. Lopez-Compos, M. Dungan, B. Utarro, and J. Aalhus. 2012. Beef texture and juiciness. In: Handbook of Meat and Meat Processing. 2nd ed. (Ed. Y. H. Hui). CRC. pp. 177-188.

Kang, J. O., H. Kamisoyama, S. Shigemori, I. Hayakawa, and T. Ito. 1991. Effect of electrical stimulation on the rheological properties of rabbit skeletal muscle. Meat Sci. 29:203-210.

Kemp, C. M., P. L. Sensky, R. G. Bardsley, P. J. Buttery, and T. Parr. 2010. Tenderness - An enzymatic view. Meat Sci. 84: 248-256.

Kerth, C., T. Cain, S. Jackson, C. Ramsey, and M. Miller. 1999. Electrical stimulation effects on tenderness of five muscles from Hampshire $\mathrm{x}$ Rambouillet crossbred lambs with the callipyge phenotype. J. Anim. Sci. 77:2951-2955.
Kim, Y., S. Lonergan, J. Grubbs, S. Cruzen, A. Fritchen, A. della Malva, R. Marino, and E. Huff-Lonergan. 2013. Effect of low voltage electrical stimulation on protein and quality changes in bovine muscles during postmortem aging. Meat Sci. 94:289296

King, D., K. Voges, D. Hale, D. Waldron, C. Taylor, and J. Savell. 2004. High voltage electrical stimulation enhances muscle tenderness, increases aging response, and improves muscle color from cabrito carcasses. Meat Sci. 68:529-535.

Kotula, A. and B. Emswiler-Rose. 1981. Bacteriological quality of hot-boned primal cuts from electrically stimulated beef carcasses. J. Food Sci. 46:471-474.

Lawrie, R. and D. A. Ledward. 2006. The storage and preservation of meat: Temperature control. In: Lawrie's Meat Science. 7th ed. Boca Raton New York Washington, DC: CRC. pp. 192-202.

Ledward, D. A., R. F. Dickinson, V. H. Powell, and W. R. Shorthose. 1986. The colour and colour stability of beef longissimus dorsi and semimembranosus muscles after effective electrical stimulation. Meat Sci. 16:245-265.

Locker, R. 1985. Cold-induced toughness of meat. 1. Electrical stimulation. In: Advances in Meat Research. (Ed. A. M. Pearson and T. R. Dutson). The AVI Publishing Company, Inc. pp. 1-44.

Martin, A. H., A. C. Murray, L. E. Jeremiah, and P. J. Dutson. 1983. Electrical stimulation and carcass aging effects on beef carcasses in relation to post-mortem glycolytic rates. J. Anim. Sci. 57:1456-1462.

McKeith, F., G. Smith, J. Savell, T. Dutson, Z. Carpenter, and D. Hammons. 1981. Effects of certain electrical stimulation parameters on quality and palatability of beef. J. Food Sci. 46:13-18.

McKenna, D., D. Maddock, and J. Savell. 2003. Water-holding and color characteristics of beef from electrically stimulated carcasses. J. Muscle Foods 14:33-49.

Meat and Livestock Australia and Australian Meat Processor Corporation 2011. Heat toughening -Part 2: Strategies for reducing the incidence of heat toughening in beef carcasses. MLA and AMPC. CSIRO pub. May 2011. pp. 1-4.

Morton, H. and R. Newbold. 1982. Pathways of high and low voltage electrical stimulation in sheep carcasses. Meat Sci. 7:285-297.

Mota-Rojas, D., P. Roldan-Santiago, and I. Guerrero-Legarreta. 2012. Electrical stimulation in meat processing. In: Handbook of Meat and Meat Processing. 2nd ed. (Ed. Y. H. Hui) CRC. pp. 323-329.

Nazli, B., O. Cetin, E. Bingol, T. Kahraman, and O. Ergun. 2010. Effects of high voltage electrical stimulation on meat quality of beef carcasses. J. Anim. Vet. Adv. 9:556-560.

Ockerman, H. and J. Szczawinski. 1983. Effect of electrical stimulation on the microflora of meat. J. Food Sci. 48:10041005.

Ockerman, H. and J. Szczawinski. 1984a. Combined effects of electrical stimulation and methods of meat preservation upon the survival of bacteria1. J. Food Process. Preserv. 8:47-56.

Ockerman, H. and J Szczawinski. 1984b. Effect of electrical stimulation of inoculated pork tissue on the thermoresistance of Lactobacillus plantarum, Pseudomonas putrefaciens and Streptococcus faecalis. J. Food Sci. 49:288-289.

Polidori, P., S. Lee, R. Kauffman, and B. Marsh. 1999. Low 
voltage electrical stimulation of lamb carcasses: Effects on meat quality. Meat Sci. 53:179-182.

Pospiech E., B. Grzés, A. Lyczýnski, K. Borzuta, M. Szalata, and B. Mikolajczak. 2003. Muscle proteins and their changes in the process of meat tenderization. Anim. Sci. Pap. Rep. 21:133151.

Prandl, O., A. Fischer, T. Schmidhofer, H. Sinell, and J. E. Escobar. 1994. Tecnologia e higiene de la carne. Editorial Acribia. pp. 124-126.

Riley, R., J. Savell, G. Smith, and M. Shelton. 1981. Improving appearance and palatability of meat from ram lambs by electrical stimulation. J. Anim. Sci. 52:522-529.

Roeber, D., R. Cannell, K. Belk, J. Tatum, and G. Smith. 2000. Effects of a unique application of electrical stimulation on tenderness, color, and quality attributes of the beef longissimus muscle. J. Anim. Sci. 78:1504-1509.

Sams A. 1999. Commercial implementation of postmortem electrical stimulation. Poult. Sci. 78:290-294.

Savell, J., S. Mueller, and B. Baird. 2005. The chilling of carcasses. Meat Sci. 70:449-459.

Savell, J., G. Smith, T. Dutson, Z. Carpenter, and D. Suter. 1977. Effect of electrical stimulation on palatability of beef, lamb and goat meat. J. Food Sci. 42:702-706.

Sleper, P., M. Hunt, D. Kropf, C. Kastner, and M. Dikeman. 1983. Electrical stimulation effects on myoglobin properties of bovine longissimus muscle. J. Food Sci. 48:479-483.

Simmons, N., C. Daly, T. Cummings, S. Morgan, N. Johnson, and A. Lombard. 2008. Reassessing the principles of electrical stimulation. Meat Sci. 80:110-122.

Smith, G. 1985. Effects of electrical stimulation on meat quality, color, grade, heat ring, and palatability. 1. Electrical stimulation. In: Advances in Meat Research (Ed. A. M. Pearson and T. R. Dutson) The AVI Publishing Company, Inc. pp. 121-158.
Soria, L. and P. Corva. 2004. Factores genéticos y ambientales que determinan la terneza de la carne bovina genetic and environmental factors influencing beef tenderness. Archivos Latinoamericanos De Producción Anim. 12:73-88.

Takahashi, G., S. Wang, J. Lochner, and B. Marsh. 1987. Effects of 2-hz and 60-hz electrical stimulation on the microstructure of beef. Meat Sci. 19:65-76.

Takahashi, K. 1992. Non-enzymatic weakening of myofibrillar structures during conditioning of meat: Calcium ions at 0.1 $\mathrm{mM}$ and their effect on meat tenderization. Biochimie 74:247250.

Taylor, A. and L. Martoccia. 1995. The effect of low voltage and high voltage electrical stimulation on pork quality. Meat Sci. 39:319-326.

Troy, D. 2006. Hot-boning of meat: A new perspective. In: Advanced Technologies for Meat Processing (Ed. M. Leo, L. Nollet, and T. Fidel). CRC Press. pp. 73-85.

Warriss, P. D. 2010. Meat science: An Introductory Text. 2nd Ed. CABI Publishing, pp. 117-122.

Wiklund, E., J. Stevenson-Barry, S. Duncan, and R. Littlejohn. 2001. Electrical stimulation of red deer (Cervus elaphus) carcasses - effects on rate of $\mathrm{pH}$-decline, meat tenderness, colour stability and water-holding capacity. Meat Sci. 59:211220.

Yanar, M. and H. Yetim. 2003. The effects of electrical stimulation on the sensory and textural quality properties of mutton carcasses. Turk. J. Vet. Anim. Sci. 27:433-438.

Young, L. L., R. J. Buhr and C. E. Lyon. 1999. Effect of polyphosphate treatment and electrical stimulation on postchill changes in quality of broiler breast meat. Poult. Sci. 78:267271.

Żywica, R. and J. K. Banach. 2003. The influence of high-voltage electrical stimulation and animals' sex on the selected attributes of quality of cooked beef hams produced from semitendinosus muscle. Food Sci. Technol. 6:1-6. 